"Investigating the efficiency of financial markets: Empirical evidence from MENA countries"

\begin{tabular}{ll} 
AUTHORS & Izzeddien N. Ananzeh \\
\hline ARTICLE INFO & $\begin{array}{l}\text { Izzeddien N. Ananzeh (2021). Investigating the efficiency of financial markets: } \\
\text { Empirical evidence from MENA countries. Investment Management and } \\
\text { Financial Innovations, 18(1), 250-259. doi:10.21511/imfi.18(1).2021.21 }\end{array}$ \\
\hline DOI & http://dx.doi.org/10.21511/imfi.18(1).2021.21 \\
\hline RELEASED ON & Monday, 15 March 2021 \\
\hline RECEIVED ON & Monday, 08 February 2021 \\
\hline ACCEPTED ON & Friday, 12 March 2021 \\
\hline LICENSE & (cc) Br \\
\hline JOURNAL & This work is licensed under a Creative Commons Attribution 4.0 International \\
\hline ISSN PRINT & "Investment Management and Financial Innovations" \\
\hline ISSN ONLINE & $1810-4967$ \\
\hline PUBLISHER & $1812-9358$ \\
\hline FOUNDER & LLC "Consulting Publishing Company "Business Perspectives" \\
\hline LLC "Consulting Publishing Company "Business Perspectives"
\end{tabular}

NUMBER OF REFERENCES

31

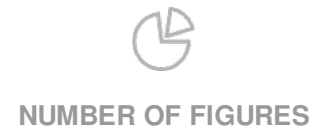

0
NUMBER OF TABLES

4

(C) The author(s) 2021. This publication is an open access article. 


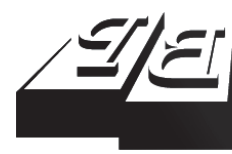

BUSINESS PERSPECTIVES

(O)

LLC "CPC "Business Perspectives" Hryhorii Skovoroda lane, 10, Sumy, 40022, Ukraine www.businessperspectives.org
Received on: $8^{\text {th }}$ of February, 2021 Accepted on: 12 $2^{\text {th }}$ of March, 2021 Published on: $15^{\text {th }}$ of March, 2021

๑) Izzeddien N. Ananzeh, 2021

Izzeddien N. Ananzeh, Associate Professor, Faculty of Business, Finance and Banking Department, Philadelphia University, Jordan.

\section{INVESTIGATING THE EFFICIENCY OF FINANCIAL MARKETS: EMPIRICAL EVIDENCE FROM MENA COUNTRIES}

\begin{abstract}
The market efficiency hypothesis has become an important concept for all investors looking to own internationally diversified portfolios, which coincides with an increase in investment flows between all countries, both developed and undeveloped. This study was aimed at investigating the efficiency of a group of Arab stock markets located in the Middle East and North Africa (MENA) region according to the Random Walk Hypotheses (RWH) at weak form. The study covered the markets of Jordan, Egypt, Saudi Arabia, UAE, Bahrain, and Oman.

The empirical results of all tests used in this study rejected the RWH at a weak form for all markets through all tests applied - Unit root test, Variance Ratio Test, and Run Test.

The result of this study contradicts the results of many studies conducted on developed and emerging markets. This can be a good indication of the ineffectiveness of the reforms that have been adopted by responsible bodies on these markets.

Based on this result, all efforts made to expand and deepen these markets should be in tensified by improving liquidity, transparency, enhancing investment culture in these countries; supporting legislative and regulatory reforms to attract investment, and developing the financial sector in these markets as a whole.
\end{abstract}

\section{Keywords}

MENA markets, market efficiency, financial markets, unit root tests, run test, variance ratio test

JEL Classification G11, G14, G15, D53

\section{INTRODUCTION}

Financial markets play a central role in any economy as they represent a point of contact between individuals and institutions, mobilizing savings and transforming them into investments that contribute to a country's economic development and provide a solid base for the national economy. For financial markets to play an active role in collecting and channeling savings from surplus units to deficit units, they must be efficient. Efficiency means that prices reflect all available information on securities. The capital market is based on the basic assumption that stock prices reflect all the available information about them, where information is the main element on which it is based (Abraham et al., 2002).

The market efficiency hypothesis emerged as a result of the efforts of a large group of researchers to study the efficiency of financial markets. The roots of this theory went back in 1888, when British researchers Lord Rayleigh and John Venn introduced the concept of random walk in general; stock prices do not follow a specific pattern to take it. Their movement is random and difficult to predict from it. In 1889, George Gibson pointed out that when stocks were put up for trading, their value reflected the best information related to it. In 1953, Kendall and 
Hill found no predictable patterns in the prices of stocks. Prices pretended to evolve randomly. Harry Roberts, in 1959, found the same result in his study related to the Dow Jones Industrial Index.

Eugene Fama is one of the most famous researchers on the subject of market efficiency. He examined the extent of the relationship between historical information and information in the future. He found no particular pattern of past price behavior that could be relied on in the future. Therefore, the share price movement is based on the hypothesis of the random walk. These results have been taken into consideration and have become an indicator of the financial market's efficiency and indicative of the market's ability to respond rapidly to any new information received in the market.

Fama (1970) designed the efficient market hypothesis and divided market efficiency into three levels, depending on the availability of information: weak form, semi-strong form, and strong form. The weak form of efficiency assumes that past price information and trading volumes of the securities have been reflected in current prices. No investor will be able to rely on past information and prices to identify incorrectly priced securities to invest in and generate abnormal returns. Semi-strong form of efficiency assumes that current prices reflect all available information to the public. This information includes past prices and any current information that affects the price, such as corporate financial reports, income statements, dividend announcements, merger plans, etc. Strong- form assumes that the current prices reflect all available information, including general and specific historical one, specifically that not available to general investors.

The hypothesis of the financial market efficiency suggested by Fama (1970) has been tested in emerging and developing markets. Studies in emerging markets have focused mainly on the weak-form efficiency, which is the lower level of the three levels. If there is no evidence to support a low level of efficiency, it is unnecessary to test efficiency at the semi-strong or strong form of efficiency. To inspect the efficiency of markets at a weak-form, many previous studies have tested the feasibility of investment strategies built on technical analysis, such as examining stock prices' predictability by testing a random walk model. This model tests whether prices are random, which means that previous prices cannot be indicative for future prices and that successive price changes must be independent of past price changes.

The idea of the efficiency of financial markets has an essential impact on fund managers, and more specifically, investors seeking to diversify their portfolios, both at the regional or international level.

The importance of this study stems from two points: first, the focus is on the important role of financial markets in promoting economic development, and the second point is that the results of this study are important for investors looking to build internationally diversified portfolios in the same region.

\section{LITERATURE REVIEW}

Several studies have been conducted to test the efficiency and integration of global financial markets. The subject of efficiency of financial markets has been studied based on the random walk hypothesis (RWH) using historical data on stock prices to predict the movement of stock prices in the future. The roots of this theory went back in 1888, when British researchers Lord Rayleigh and John Venn introduced the concept of random walk in general; stock prices do not follow a specific pattern to take it. Their movement is random and difficult to predict from it. In 1889 , George Gibson pointed out that when stocks were put up for trading, their value reflected the best information related to it. In 1953, Kendall and Hill found no predictable patterns in the prices of stocks. Prices pretended to evolve randomly. Harry Roberts, in 1959 , found the same result in his study related to the Dow Jones Industrial Index.

Fama (1965) was one of the first studies to test the efficiency of the market at the weak form. The researcher examined the randomness of prices for 30 companies listed in the DJIA from 1956 to 1961 and used many tests to inspect RWH. He confirmed the randomness of stock prices under study and the concept of the efficient market used for the first time. 
Fama (1970) put the theoretical and practical aspects of the financial market efficiency model. He divided the Efficient Market Hypothesis (EMH), based on the information, into three hypotheses; the first is the weak form, the second is the semi-strong form, and the last is the strong form. EMH proposed by Fama (1970) was tested in both developed and emerging financial markets. Studies in emerging markets have focused mainly on the weak form. A little evidence supports the efficiency at this level so that it is not necessary to test efficiency at a semi-strong or strong form.

Fama and French (1988) inspect industry portfolio data for the period from 1926 to 1985 , and their results refer to a negative autocorrelation of the return horizon for the industry portfolio. RWH was rejected firmly by Lo and MacKinlay (1988), who utilized the index of NYSE. Hawaii in 1984, Fama in 1991, and Lo in 1997 found empirical evidence supporting the EMH theory in both developed and emerging countries.

A study of the financial literature detected many publications that tested the existence of efficient market hypotheses in several developed and underdeveloped markets with mixed results like Dahel and Laabas (1999), Ozdemir (2008), Ananzeh (2014), Awan and Subayyal (2016) and many more. In four emerging stock markets, Urrutia (1995) inspected the RWM for the test period span from 1975 to 1991. Using the variance ratio test, he rejects the RWH, and his finding supports the weak form of efficiency related to those markets through the run test.

Abraham et al. (2002) indicated the need to adjust data used because of the impact of infrequent trading. They examined the efficiency of some major Gulf markets (Kuwait, Saudi Arabia, Bahrain) from 1992 to1998 using weekly data for those markets. The study found that the efficiency at the weak level was rejected for all markets when using original data. Still, after modifying the data with the effect of infrequent trading, the hypothesis was not rejected, meaning that the three studied Gulf markets are efficient at the weak level.

Squalli (2006) used daily data for both Abu Dhabi and Dubai stock exchanges from 2000 to 2005 to test a random walk hypothesis. Based on the results of the variance ratio test, with the exception of the banking sector in the Dubai Stock Exchange, the RWH was rejected, while the results of the run test found that the insurance sector in the Abu Dhabi Stock Exchange was the only efficient sector at the weak level.

Caio et al. (2007), using the Granger causality test and co-integration analysis, examine the efficiency of the Brazilian stock market (semi-strong efficiency). They found that the Brazilian stock market was inefficient.

Using the unit root and co-integration tests Korkmaz and Akman (2010) inspect the efficiency of the Istanbul Stock Exchange (ISE) 100 (XU100) at the weak form for the period 2003-2009. The results of this study show that the ISE was efficient at the weak level. Jamaani and Roca (2015) examine the efficiency of six stock markets in the Arab Gulf region, and their finding represents for no evidence of the weakform efficiency in these markets.

Awan and Subayyal (2016) examined the six financial markets in the Gulf region (Bahrain, Saudi Arabia, Kuwait, UAE, Oman, and Qatar) for the period 2011 to 2015. The results of this study show that the stock prices for these markets do not follow the RWH. Guermezi and Boussaada (2016) examined EMH at the weak form for the Tunisian Stock Market (TSM), and concluded that TSM was not efficient at the weak form, especially the banking sector. Chaker and Sabah (2018) examined the EMH in all Arab Gulf financial markets, except for Qatar markets, for the period 2013-2017 using unit root tests, variance ratio test, and run test. The results of this study show that stock prices for these markets do not follow the RWH.

Kiran and Rao (2019) examine the EMH of stock markets of several countries (Brazil, Russia, India, China and South Africa) called BRICS markets. The testing covers the period from 1997 to 2018, and the hall period is divided into sub-periods. The results of this study show that in the full period, Russia and South Africa are efficient at the weak form, and Brazil and China markets are efficient all the time. But in the full period, the Indian stock market was weakly efficient. This is the result of the variance ratio test, but the results of the nonlinear test show that all BRICS markets are inefficient. 
Khoj and Akeel (2020) investigate the efficiency of the Saudi Arabia stock market at the weak form from 2012 to 2019. They conclude that the stock market of Saudi Arabia is not efficient at the weak form.

All previous literature has shown different results for various countries, be it developing or developed markets. Therefore, the aim of this study is to inspect the RWH for a group of countries that fall within the same region in the Middle East and North Africa (MENA) markets from January 2009 to January 2019, and to compare the results of the studied markets.

\section{DATA, METHODOLOGY AND HYPOTHESES DEVELOPMENT}

This study examines the efficiency of selected Arab Financial Markets (AFM) at the weak form according to the Random Walk Hypotheses (RWH) adopted by the American economist (Fama). To inspect this efficiency level, changes in stock prices must be independent and identically distributed (IDD). Hence, the price trend cannot be used for forecasting future movements or prices, and then the market efficiency will be achieved at the weak level.

The null hypothesis is as follows:

$$
\begin{aligned}
& H_{0}: \quad \begin{array}{l}
\text { Arab Stock Markets (ASM) are not efficient } \\
\text { at the weak form. }
\end{array}
\end{aligned}
$$

The alternative hypothesis is:

$H_{1}: \quad$ Arab Stock Markets (ASM) are efficient at the weak form.

This paper used daily data for Arab Stock Markets' (ASM) indices. This study covered the period from January 2009 to January 2019 for each of the markets (Jordan, Egypt, Saudi Arabia, UAE, Bahrain, Oman), and all data was obtained from the website http://www.arab-exchanges.org/. The daily rate of returns for the indices was calculated using the following formula:

$$
M R T_{T}=\ln \left(\frac{P_{T}}{P_{T-1}}\right),
$$

where $P_{T}$ indicates the closing price of the Arab Stock Markets Indices (ASMI) under study. $P_{T-1}$ indicates the previous day's closing price of the Arab Stock Markets Indices (ASMI) under study.

This study examines the efficiency of financial markets at a weak level, according to the Random Walk Hypothesis (RWH) adopted by the American economist Fama. To examine this level of efficiency, he declared that changes in stock prices must be independent and identically distributed (IID). Consequently, the price trend cannot be used to predict future movements of prices, and then the market efficiency will be achieved at a weak level.

This paper follows the previous literature by adopting various econometric techniques to examine the independence of the stock prices and analyze the random walk hypothesis (RWH) for Arab Stock Markets (ASM) under study. The paper employed many parametric and non-parametric techniques.

\subsection{Unit root tests}

To inspect the stationarity of Arab Stock Markets Indices (ASMI) under study, which is necessary for RWH, this paper utilized two Unit Root tests such as Augmented Dickey-Fuller (ADF) (1979) and Phillips-Peron (PP) (1988) tests.

ADF test is based on the following formula:

$$
\begin{aligned}
& \Delta M R T_{T}=\gamma_{0}+\gamma_{1} M R T_{T-1}+\gamma_{2} T+ \\
& +\sum_{T=1}^{m} \gamma_{i} \Delta M R T_{T-i}+\varepsilon_{T},
\end{aligned}
$$

where $\Delta$ indicates the first difference operator, $M R T$ indicates the daily market return, and $\varepsilon_{T}$ indicates the error term. The null hypothesis to inspect the unit root test is as follows:

$$
H_{0}: \gamma_{1}=0 \text { versus } H_{1}: \gamma_{1}<0
$$

Phillip-Peron test differs from ADF tests in how to deal with and manipulate serial correlation and heterogeneity in error. It was based on the ADF regression equation itself and made a modification on the ADF test using Z-statistics. The following estimation formula is: 


$$
\Delta M R T_{t}=\gamma_{t}+\beta\left(M R T_{t-1}\right)+\varepsilon_{t},
$$

In two cases, $\mathrm{ADF}$ and $\mathrm{PP}$, the null hypothesis is that the return series is non-stationary.

\subsection{Variance ratio test (VR)}

The Variance Ratio test (VR) was proposed by Lo and MacKinlay (1988) and Cochrane (1988). This test is considered equivalent to the unit root test's strength and is, therefore, widely used in recent studies that inspect the efficiency of financial markets at a weak level. The test is based on the assumption that the variance of time series runs randomly. It increases linearly with time, and precisely if the series of returns follow a random course, then the variance of the $q^{\text {th }}$ differences of the series must be $q$ times the variance of its first differences.

With homoscedasticity and using overlapping observations, the variance ratio test is as follows:

$$
V A R_{q}=\frac{\sigma_{a}^{2}(q)}{\sigma_{d}^{2}(1)} .
$$

The unbiased estimators $\sigma_{a}^{2}(q)$ refer to the variance of the $q^{\text {th }}$ differences, and $\sigma_{a}^{2}(1)$ refers to the variance of the first difference.

Lo and Mackinlay (1988) developed two statistical tests. The first variance ratio test under homoscedasticity $Z(q)$ is:

$$
Z_{Q}=\frac{\left(V R_{q}-1\right)}{\left[\vartheta_{q}\right]^{1 / 2}} \sim N(0,1),
$$

where $\vartheta_{q}=2(2 q-1)(q-1) / 3 q(n)$.

Under heteroscedasticity, the variance ratio test is:

$$
Z_{q}^{*}=\frac{\left(V R_{q}-1\right)}{\left[\vartheta_{q}^{*}\right]^{1 / 2}} \sim N(0,1),
$$

where $\vartheta_{q}^{*}=\sum_{k=1}^{q-1}\left(2(q-k)^{2} / q\right) \sigma^{\wedge} k$.

The hypothesis by which RWH is tested can be formulated as follows:
$H_{0}$ : The variance ratio for all chosen collection periods $q$ is equal to one.

According to Squalli (2006), if the random walk hypothesis is rejected and the variance ration is greater than one, higher $\mathrm{Z}$ value, the returns will be positively serially correlated, and the market will be efficient at the weak form.

\subsection{Run test}

It is a non-parametric test designed to check the randomness in the time series, especially those that are not normally distributed. The test inspects if the direction of one observation influences the directions taken in later observations. This test is based on the assumption that if the time series is randomly fluctuated and independent, then the number of actual runs in the series should be close to the expected number of runs.

The total number of runs can be calculated by the following equation:

$$
k=\frac{N\{N+1\}-\sum_{i=1} n_{i}^{2}}{N},
$$

where $N$ refers to the number of observations, and $n_{i}$ refers to the number of price changes. To implement the run test, normal Z-statistics can be used through the following formula:

$$
Z=\{r \pm 0.05-\tau\} / \sigma_{\tau}
$$

where $r$ : points to the actual number of runs, and $\sigma_{\tau}$ points to the expected number of runs.

\section{ANALYSES, RESULTS AND DISCUSSIONS}

It is necessary to examine the efficiency of selected Arab Financial Markets (AFM) under study in a weak form, depending on the Random Walk Hypothesis (RWH). This paper employed many statistical methods that were used in previous studies: unit root test through Augmented

$$
\sigma^{\wedge} k=\frac{\sum_{i=k+1}^{q-1}\left(M R T_{i}-M R T_{i-1}-\partial^{\wedge}\right)^{2}\left(M R T_{i-k}-M R T_{i-k-1}-\partial^{\wedge}\right)^{2}}{\left\{\sum_{i=1}^{n}\left(M R T_{i}-M R T_{i-1} \partial^{\wedge}\right)^{2}\right\}^{2}} .
$$


Dickey-Fuller test (ADF), as well as Phillip-Peron test (PP), Variance Ratio test (VR) conducted on the assumption of Homoscedasticity and Heteroscedasticity, and Run Test.

\subsection{Descriptive statistics}

To begin with, to review the primary feature of the data, Table 1 presents a set of descriptive statistics and a normal distribution of Arab Stock Market Indices (ASMI) for the period from January 2009 to January 2019.

Table 1 shows that the hall sample's average returns are positive, except for Jordan and Oman. Standard deviations did not exceed $2.07 \%$. The results also indicated skewness and kurtosis in distributing ASM returns compared to the normal distribution. Consequently, the returns series of Arab Stock markets' indices do not follow the normal distribution according to the Jarque-Bera test results at the $1 \%$ and $5 \%$ significance levels.

\subsection{Unit root tests}

The first approach used to inspect the efficiency of the Arab Stock Markets is Unit Root tests. Augmented Dickey-Fuller (ADF) and PhillipPeron (PP) tests are used to inspect the stationarity of ASMI returns. The results of the two tests are shown in Table 2.

Table 2 indicates that the values of the ADF and PP tests calculated (with intercept, with intercept and trend, without intercept and trend) for all return series of ASMI under study are stationary. The tests statistic values were much more negative than the (critical) tabular value of the tests at the significance levels of $1 \%, 5 \%$, and $10 \%$; this result means rejecting the null hypothesis of RW and supporting the inefficiency of Arab Stock Markets under study at a weak form.

\subsection{Variance ratio test (VR)}

The presence of heteroscedasticity in returns may be a reason for rejecting EMH in the weak form. Lo and Mackinlay (1988) indicated that market efficiency at the weak form could be inspected by using the Variance ratio test (VR), which is suitable for all autocorrelation cases; heteroscedasticity and non-normal distribution of returns.

In this study the variance ratio test is conducted through two cases: heteroscedasticity and homoscedasticity in returns.

Table 3 shows the variance ratio test results, depending on daily values of Arab Stock Market Indices under study. Depending on the values of $Z(q)$ and $Z^{*}(q)$ statistics for the null hypothesis, the variance ratios equal one, and the Arab Stock Markets indices follow the random walk hypotheses. The results of all test statistics are reported in Table 3: whether assuming homoskedasticity or heteroskedasticity is significant, and the random walk hypothesis is rejected. This confirms the inefficiency of Arab Stock Markets under study at the weak form.

Table 1. Descriptive statistics

\begin{tabular}{|c|c|c|c|c|c|c|}
\hline & Jordan & Egypt & Saudi Arabia & UAE/Dubai & Bahrain & Oman \\
\hline Mean & -0.00054 & 0.00055 & 0.000298 & 0.000291 & $2.04 \mathrm{E}-05$ & -0.00012 \\
\hline Median & -0.0001 & 0.001 & 0.0006 & 0.0001 & 0 & 0 \\
\hline Maximum & 0.0239 & 0.0759 & 0.0892 & 0.1298 & 0.0279 & 0.0612 \\
\hline Minimum & -1 & -0.1052 & -0.0727 & -0.0761 & -0.028 & -0.0629 \\
\hline Std. dev. & 0.020755 & 0.015456 & 0.011149 & 0.015298 & 0.004575 & 0.007648 \\
\hline Skewness & -44.8677 & -0.36713 & -0.46353 & 0.189261 & -0.19279 & -0.46831 \\
\hline Kurtosis & 2161.23 & 7.096365 & 12.12152 & 10.31553 & 7.072649 & 19.30302 \\
\hline Jarque-Bera & $4.84 E+08$ & 1752.863 & 9106.661 & 5620.914 & 1633.07 & 28888.8 \\
\hline Probability & 0 & 0 & 0 & 0 & 0 & 0 \\
\hline Sum & -1.3324 & 1.3354 & 0.7741 & 0.7306 & 0.0477 & -0.3028 \\
\hline Sum sq. dev. & 1.072228 & 0.58003 & 0.323069 & 0.588143 & 0.048995 & 0.15202 \\
\hline Observations & 2,490 & 2,429 & 2,600 & 2,514 & 2,342 & 2,600 \\
\hline
\end{tabular}


Table 2. Unit root test results

\begin{tabular}{|c|c|c|c|c|c|c|c|c|c|c|}
\hline & $\begin{array}{c}\text { ADF } \\
t \text {-stat }\end{array}$ & At $1 \%$ & $5 \%$ & $10 \%$ & Prob. & $\begin{array}{c}\text { PP } \\
t \text {-stat }\end{array}$ & At $1 \%$ & $5 \%$ & $10 \%$ & Prob. \\
\hline \multicolumn{11}{|c|}{ Jordan } \\
\hline With intercept & -36.66 & -3.43 & -3.43 & -3.43 & 0.00 & -36.61 & -36.61 & -36.61 & -36.6 & 0.00 \\
\hline With intercept and trend & -36.64 & -36.6 & -36.6 & -36.6 & 0.00 & -36.59 & -36.59 & -36.59 & -36.5 & 0.00 \\
\hline $\begin{array}{l}\text { Without intercept and } \\
\text { trend }\end{array}$ & -36.619 & -36.61 & -36.61 & -36.61 & 0.00 & -36.60 & -36.604 & -36.604 & -36.60 & 0.00 \\
\hline \multicolumn{11}{|c|}{ Egypt } \\
\hline With intercept & -40.32 & -3.43 & -2.86 & -2.56 & 0.00 & -40.32 & -3.432 & -2.862 & -2.56 & 0.00 \\
\hline With intercept and trend & -40.31 & -3.96 & -3.41 & -3.12 & 0.00 & -40.31 & -3.961 & -3.411 & -3.12 & 0.00 \\
\hline $\begin{array}{l}\text { Without intercept and } \\
\text { trend }\end{array}$ & -40.28 & -2.56 & -1.94 & -1.61 & 0.00 & -40.26 & -2.565 & -1.940 & -1.61 & 0.00 \\
\hline \multicolumn{11}{|c|}{ Saudi Araba } \\
\hline With intercept & -46.19 & -3.43 & -2.86 & -2.56 & 0.00 & -46.25 & -3.432 & -2.862 & -2.56 & 0.00 \\
\hline With intercept and trend & -46.18 & -3.96 & -3.41 & -3.12 & 0.00 & -46.24 & -3.961 & -3.411 & -3.12 & 0.00 \\
\hline $\begin{array}{l}\text { Without intercept and } \\
\text { trend }\end{array}$ & -46.17 & -2.56 & -1.94 & -1.61 & 0.00 & -46.23 & -2.565 & -1.940 & -1.61 & 0.00 \\
\hline \multicolumn{11}{|c|}{ UAE/Dubai } \\
\hline With intercept & -32.457 & -3.432 & -2.862 & -2.567 & 0.00 & -48.26 & -3.432 & -2.862 & -2.56 & 0.00 \\
\hline With intercept and trend & -32.465 & -3.961 & -3.411 & -3.127 & 0.00 & -48.27 & -3.961 & -3.411 & -3.12 & 0.00 \\
\hline $\begin{array}{l}\text { Without intercept and } \\
\text { trend }\end{array}$ & -32.451 & -2.565 & -1.940 & -1.616 & 0.00 & -48.26 & -2.565 & -1.940 & -1.61 & 0.00 \\
\hline \multicolumn{11}{|c|}{ Bahrain } \\
\hline With intercept & -30.238 & -3.432 & -2.862 & -2.567 & 0.00 & -46.00 & -3.432 & -2.862 & -2.567 & 0.00 \\
\hline With intercept and trend & -30.31 & -3.96 & -3.41 & -3.127 & 0.00 & -45.95 & -3.961 & -3.411 & -3.127 & 0.00 \\
\hline $\begin{array}{l}\text { Without intercept and } \\
\text { trend }\end{array}$ & -30.24 & -2.56 & -1.94 & -1.616 & 0.00 & -46.01 & -2.565 & -1.940 & -1.616 & 0.00 \\
\hline \multicolumn{11}{|c|}{ Oman } \\
\hline With intercept & -38.47 & -3.432 & -2.86 & -2.567 & 0.00 & -37.58 & -3.432 & -2.862 & -2.567 & 0.00 \\
\hline With intercept and trend & -38.50 & -3.96 & -3.41 & -3.127 & 0.00 & -37.48 & -3.961 & -3.411 & -3.127 & 0.00 \\
\hline $\begin{array}{l}\text { Without intercept and } \\
\text { trend }\end{array}$ & -38.47 & -2.56 & -1.94 & -1.616 & 0.00 & -37.59 & -2.565 & -1.940 & -1.616 & 0.00 \\
\hline
\end{tabular}

Note: ${ }^{*}$ and ${ }^{* *}$ refer to the $5 \%$ and $1 \%$ significance levels, respectively.

Table 3. Variance ratio (VR) test results

\begin{tabular}{|c|c|c|c|c|c|}
\hline \multirow{2}{*}{ Markets indices } & \multirow{2}{*}{ Test-statistics } & \multicolumn{4}{|c|}{ Time horizon $q$} \\
\hline & & $q=2$ & $q=4$ & $q=8$ & $q=16$ \\
\hline \multirow{3}{*}{ Jordan } & $\mathrm{VR}(\mathrm{q})$ & 0.494556 & 0.249135 & 0.124697 & 0.063715 \\
\hline & $Z(q)$ & $-25.33784^{*}$ & $-20.11982^{*}$ & $-14.83375^{*}$ & $-10.66310^{*}$ \\
\hline & $Z *(q)$ & $-10.26247^{*}$ & $-9.860011^{*}$ & $-8.592900^{*}$ & $-7.038618^{*}$ \\
\hline \multirow{3}{*}{ Egypt } & $V R(q)$ & 0.427950 & 0.268263 & 0.135282 & 0.084331 \\
\hline & $Z(q)$ & $-19.6138^{*}$ & $-18.1839^{*}$ & $-14.0831^{*}$ & $-10.3039^{*}$ \\
\hline & $z^{*}(q)^{*}$ & $-14.15668^{*}$ & $-11.27615^{*}$ & $-10.16565^{*}$ & $-8.397789^{*}$ \\
\hline \multirow{3}{*}{ Saudi Arabia } & $V R(q)$ & 0.541812 & 0.283380 & 0.139751 & 0.066928 \\
\hline & $Z(q)$ & $-23.35859^{*}$ & $-19.52801^{*}$ & $-14.82597^{*}$ & $-10.77812^{*}$ \\
\hline & $z^{*}(q)$ & $-12.53851^{*}$ & $-11.95031^{*}$ & $-10.75364 *$ & $-9.079277^{*}$ \\
\hline \multirow{3}{*}{ UAE/Dubai } & $\operatorname{VR}(q)$ & 0.488601 & 0.260335 & 0.132668 & 0.065614 \\
\hline & $Z(q)$ & $-25.63632^{*}$ & $-19.81970^{*}$ & $-14.69865^{*}$ & $-10.64148^{*}$ \\
\hline & $z^{*}(q)$ & $-11.12112^{*}$ & $-10.59012^{*}$ & $-9.834551^{*}$ & $-8.050127^{*}$ \\
\hline \multirow{3}{*}{ Bahrain } & $\operatorname{VR}(q)$ & 0.538405 & 0.256150 & 0.165982 & 0.150593 \\
\hline & $z(q)$ & $-25.20462 *$ & $-19.31059 *$ & $-14.21475^{*}$ & $-10.26203^{*}$ \\
\hline & $Z^{*}(q)$ & $-11.50292^{*}$ & $-10.70744^{*}$ & $-8.942519^{*}$ & $-7.055589 *$ \\
\hline \multirow{3}{*}{ Oman } & $\operatorname{VR}(q)$ & 0.656274 & 0.357429 & 0.175621 & 0.081893 \\
\hline & $z(q)$ & $-17.52331^{*}$ & $-17.51017^{*}$ & $-14.20778^{*}$ & $-10.63348^{*}$ \\
\hline & $Z^{*}(q)$ & $-12.49346^{*}$ & -11.82342 & -10.14895 & $-8.513379 *$ \\
\hline
\end{tabular}

Note: $V R(q)$ points to the variance ratio; $Z(q)$ points to the test statistic for the null hypothesis of homoscedasticity; $Z^{*}(q)$ points to the test statistic for the null hypothesis of heteroskedasticity; ${ }^{*}$ indicates the $1 \%$ significance level, and $* *$ the $5 \%$ significance level. 
Table 4. Runs test results

\begin{tabular}{l|c|c|c|c|c|c}
\hline & Jordan & Egypt & $\begin{array}{c}\text { Saudi } \\
\text { Arabia }\end{array}$ & UAE/Dubai & Bahrain & Oman \\
\hline Test value (Median) & .0001 & .0010 & .0006 & .0001 & .0000 & .0000 \\
Cases < Test value & 1245 & 1214 & 1360 & 1257 & 1171 & 1326 \\
Cases $\geq$ Test value & 1245 & 1215 & 1361 & 1257 & 1171 & 1363 \\
Total cases & 2490 & 2429 & 2721 & 2514 & 2342 & 2689 \\
Number of runs & 1153 & 1086 & 1228 & 1253 & 1121 & 1057 \\
Z & $-3.728-$ & $-5.256-$ & $-5.119-$ & $-199-$ & $-2.108-$ & $-11.121-$ \\
Asymp. sig. (2-tailed) & .000 & .000 & .000 & .042 & .035 & .000 \\
\hline
\end{tabular}

\subsection{Runs test}

The first approach used to inspect the efficiency of the Arab Stock Markets is the Runs Test. It is a non-parametric test designed to check the randomness in the time series, especially those that are not normally distributed.
Based on the Run Test results, which is reported in Table 4, the actual number of runs for all ASM is significantly smaller than the hypothesized number of runs at $1 \%$. The estimated $\mathrm{Z}$-values are significant at the same level. This verifying that ASM returns series are not random (or nonrandom walk) behavior.

\section{CONCLUSION AND RECOMMENDATIONS}

This study is aimed at investigating the efficiency of a group of Arab Stock Markets located in the Middle East and North Africa countries according to the Random Walk Hypotheses (RWH) at the weak form. The study covered the following countries: Jordan, Egypt, Saudi Arabia, UAE, Bahrain, and Oman.

This study was carried out due to conflicting results of previous studies conducted on these markets, as well as due to the importance of these markets, which are located in the same geographical area, and the movement of investments between them.

The empirical results of all tests applied - unit root test, variance ratio test, and run test - reject the Random Walk Hypothesis at the weak form for all markets covered in this study. This means that all stock markets in these countries are inefficient at the weak level.

The results of this study have largely confirmed the results of some previous studies, which reported the inefficiency of these markets at the weak level, despite the best efforts made by these countries to update many legislations related to stimulating investments.

This can be a good indication of the ineffectiveness of the reforms that have been adopted by responsible bodies in these markets.

Based on this result, all countries should make every effort to expand and deepen these markets by improving liquidity, transparency, enhancing investment culture in these countries, supporting legislative and regulatory reforms to attract investment, and developing the financial sector in these markets as a whole.

\section{AUTHOR CONTRIBUTIONS}

Conceptualization: Izzeddien N. Ananzeh.

Data curation: Izzeddien N. Ananzeh.

Formal analysis: Izzeddien N. Ananzeh. 
Investigation: Izzeddien N. Ananzeh.

Project administration: Izzeddien N. Ananzeh.

Resources: Izzeddien N. Ananzeh.

Supervision: Izzeddien N. Ananzeh.

Validation: Izzeddien N. Ananzeh.

Visualization: Izzeddien N. Ananzeh.

Writing - original draft: Izzeddien N. Ananzeh.

Writing - review \& editing: Izzeddien N. Ananzeh.

\section{ACKNOWLEDGMENT}

This paper is supported by the Deanship of Scientific Research and Graduate Studies at Philadelphia University in Jordan.

\section{REFERENCES}

1. Abdmoulah, W. (2010). Testing the evolving efficiency of Arab stock markets. International Review of Financial Analysis, 19(1), 25-34. https://doi.org/10.1016/j. irfa.2009.11.004

2. Abraham, A., Seyyed, F. J., \& Alsakran, S. A. (2002). Testing the random walk behavior and efficiency of the Gulf stock markets. Financial Review, 37(3), 469-480. https://doi. org/10.1111/0732-8516.00008

3. Ananzeh, I. E. N. (2014). Testing the weak form of efficient market hypothesis: Empirical evidence from Jordan. International Business and Management, 9(2), 119-123. Retrieved from http:// www.cscanada.net/index.php/ $\mathrm{ibm} /$ article/view/5524

4. Awad, I., \& Daraghma, Z. (2009). Testing the weak-form efficiency of the Palestinian securities market. International Research Journal of Finance and Economics, 32, 7-17. Retrieved from https:// www.researchgate.net/publication/242094653_Testing_the Weak-Form_Efficiency_of_the_ Palestinian_Securities_Market

5. Awan, U., \& Subayyal, M. (2016). Weak form efficient market hypothesis study: Evidence from Gulf stock markets. The 2016 WEI International Academic Conference Proceedings (pp. 218-231). Boston, USA. Retrieved from https://www. westeastinstitute.com/wp-content/
uploads/2016/09/U.-F.-Awan-M. Subayyal.pdf

6. Caio, G., Meurer, R., \& Da Silva, S. (2006). Informational inefficiency of the Brazilian stockmarket (MPRA Paper, 1980). Retrieved from https://mpra.ub.unimuenchen.de/1980/

7. Chaker, M. N., \& Sabah, A. (2018). Testing the weak form of efficiency of the stock markets in Gulf Cooperation Council countries. Journal for Global Business Advancement, 11(3), 376-392. https://doi.org/10.1504/ JGBA.2018.096334

8. Cochrane, J. H. (1988). How big is the random walk in GNP? Journal of Political Economy, 96(5), 893920. Retrieved from https://www. jstor.org/stable/1837240

9. Dahel, R., \& Laabas, B. (1999, June). The behaviour of stock prices in the GCC markets. Economic Research Forum for the Arab Countries. Iran \& Turkey. Retrieved from https://www. econbiz.de/Record/workingpaper-series-economic-researchforum-for-the-arab-countriesiran-and-turkey/10009267354

10. Dickey, D. A., \& Fuller, W. A. (1979). Distribution of the estimators for autoregressive time series with a unit root. Journal of the American Statistical Association, 74(366a), 427-431. https://doi.org/10.1080/01621459. 1979.10482531
11. Fama, E. F. (1965). Portfolio analysis in a stable Paretian market. Management Science, 11(3), 404-419. http://dx.doi. org/10.1287/mnsc.11.3.404

12. Fama, E. F. (1970). Efficient capital markets: A review of theory and empirical work. The Journal of Finance, 25(2), 383-417.

13. Fama, E. F. (1991). Efficient capital markets: II. The Journal of Finance, 46(5), 1575-1617. https:// doi.org/10.1111/j.1540-6261.1991. tb04636.x

14. Fama, E. F., \& French, K. R. (1988). Permanent and temporary components of stock prices. Journal of Political Economy, 96(2), 246-273. http://dx.doi. org/10.1086/261535

15. Gibson, G. R. (1889). The Stock Exchanges of London. Paris, and New York: a comparison (GP Putnam's Sons, New York).

16. Guermezi, F. S., \& Boussaada A. (2016). The weak form of informational efficiency: case of Tunisian banking sector. Ecoforum Journal, 5(1), 22-34. Retrieved from http://ecoforumjournal.ro/index.php/eco/article/ view/338/197

17. Hawawini, G. A. (1984). European equity markets: Price behavior and efficiency (No. 4-5). Salomon Brothers Center for the Study of Financial Institutions, Graduate School of Business Administration, New York University. 
18. Jamaani, F., \& Roca, E. (2015). Are the regional Gulf stock markets weak-form efficient as single stock markets and as a regional stock market? Research in International Business and Finance, 33, 221246. https://doi.org/10.1016/j. ribaf.2014.09.001

19. Jaradat, M., Al-Zeaud, H. A., \& Al-Rawahneh, H. (2011). An econometric analysis of the determinants of inflation in Jordan. Middle Eastern Finance and Economics, 15, 120-132. Retrieved from https://eis.hu.edu. jo/Deanshipfiles/pub21221377.pdf

20. Kendall, M. G., \& Hill, A. B. (1953). The analysis of economic time-series-part I: Prices. Journal of the Royal Statistical Society. Series A (General), 116(1), 11-34. https://doi.org/10.2307/2980947

21. Khoj, H., \& Akeel, H. (2020). Testing weak-form market efficiency: the case of Saudi Arabia. Asian Economic and Financial Review, 10(6), 644. Retrieved from http://www.aessweb.com/pdf-files/ AEFR-2020-10(6)-644-653.pdf

22. Kiran, S., \& Rao, R. P. (2019). Analysis of Stock Market Efficiency in Emerging Markets: Evidence from BRICS. Romanian Economic Journal, 22(72), 6077. Retrieved from http://www. rejournal.eu/sites/rejournal. versatech.ro/files/articole/201906-25/3560/5sivakiran.pdf

23. Korkmaz, M., \& Akman, G. (2010). Testing the weak form market efficiency on Istanbul Stock Exchange. Trakia Journal of Sciences, 8(3), 39-49. Retrieved from http://tru.uni-sz.bg/tsj/ vol8N3_2010/M.Korkmaz.pdf

24. Lo, A. W. (1997). Market Efficiency. Edward Elgar Publishing.

25. Lo, A. W., \& MacKinlay, A. C. (1988). Stock market prices do not follow random walks: Evidence from a simple specification test. The Review of Financial Studies, 1(1), 41-66. Retrieved from https://www.researchgate.net/ publication/5216689_Stock_Market_Prices_do_not_Follow_Random_Walks_Evidence_from_a_ Simple_Specification_Test

26. Marashdeh, H., \& Shrestha, M. B. (2008). Efficiency in emerging markets-evidence from the Emirates securities market. European Journal of Economics, Finance and Administrative Sciences, 12(12), 143-150. Retrieved from https:// www.academia.edu/34128544/ Efficiency_in_emerging_markets_Evidence_from_the_Emirates_Securities_Market
27. Ozdemir, Z. A. (2008). Efficient market hypothesis: evidence from a small open-economy. Applied Economics, 40(5), 633-641. https://doi. org/10.1080/00036840600722315

28. Perron, P. (1988). Trends and random walks in macroeconomic time series: Further evidence from a new approach. Journal of Economic Dynamics and Control, 12(2-3), 297-332. https://doi.org/10.1016/01651889(88)90043-7

29. Roberts, H. V. (1959). Stockmarket "patterns" and financial analysis: methodological suggestions. The Journal of Finance, 14(1), 1-10. https://doi. org/10.1111/j.1540-6261.1959. tb00481.x

30. Squalli, J. (2006). A nonparametric assessment of weak-form efficiency in the UAE financial markets. Applied Financial Economics, 16(18), 1365-1373. https://doi. org/10.1080/09603100500447594

31. Urrutia, J. L. (1995). Tests of random walk and market efficiency for Latin American emerging equity markets. Journal of Financial Research, 18(3), 299-309. https://doi. org/10.1111/j.1475-6803.1995 tb00568.x 